\title{
Botulinum toxin: endoscopic treatment in fecal incontinence after ileoanal anastomosis
}

Botulinum toxin $\mathrm{A}$ is used in gastroparesis treatment [1], esophagus motility disorders [2], and anal fissures [3]. Botulinum toxin A injection after proctectomy was proposed more recently by our team for treating fecal incontinence [4]. Its use in treating fecal incontinence after ileoanal anastomosis has never been studied in humans. We report the first case of ileal botulinum toxin $\mathrm{A}$ injections in a human after ileoanal anastomosis.

A 42-year-old woman presented with chronic non-bloody diarrhea and fecal incontinence after ileoanal anastomosis. Laparoscopic coloproctectomy with an ileal J-pouch had been performed 9 years before because of refractory ulcerative colitis. Biological tests, biopsies and endoscopic investigations were normal. Anorectal manometry was performed, and no hypercontractile reservoir was noted. Assessment of the anal sphincter was normal. Her stool diary showed a mean of 59.8 stools per week ( $>$ Fig. 1 ) on a maximum dose of loperamide and codeine. The Cleveland Clinic score was 18/20; the fecal incontinence quality of life scale was 12.7 .

Ten injections of Dysport (Ipsen Limited, Slough, Berkshire, UK) botulinum toxin A (50 UI each diluted in $1 \mathrm{~mL}$ of saline solution) were administered through a 0.5-mm sclerotherapy needle during flexible ileoscopy, with the patient unanesthetized ( $\triangleright$ Video 1 ). The procedure took approximately 10 minutes. At month 7 , a reduction of 11 stools per week was observed. At months 8, 15, and 22, new injections of $500 \mathrm{UI}$ Dysport were given via the same modalities. The patient regarded clinical improvement as insufficient ( Fig. 1). Thus, a switch to an injection of 200 UI Botox (Allergan, Irvine, (A, USA) was decided. During the next 3 months, the patient recorded an average

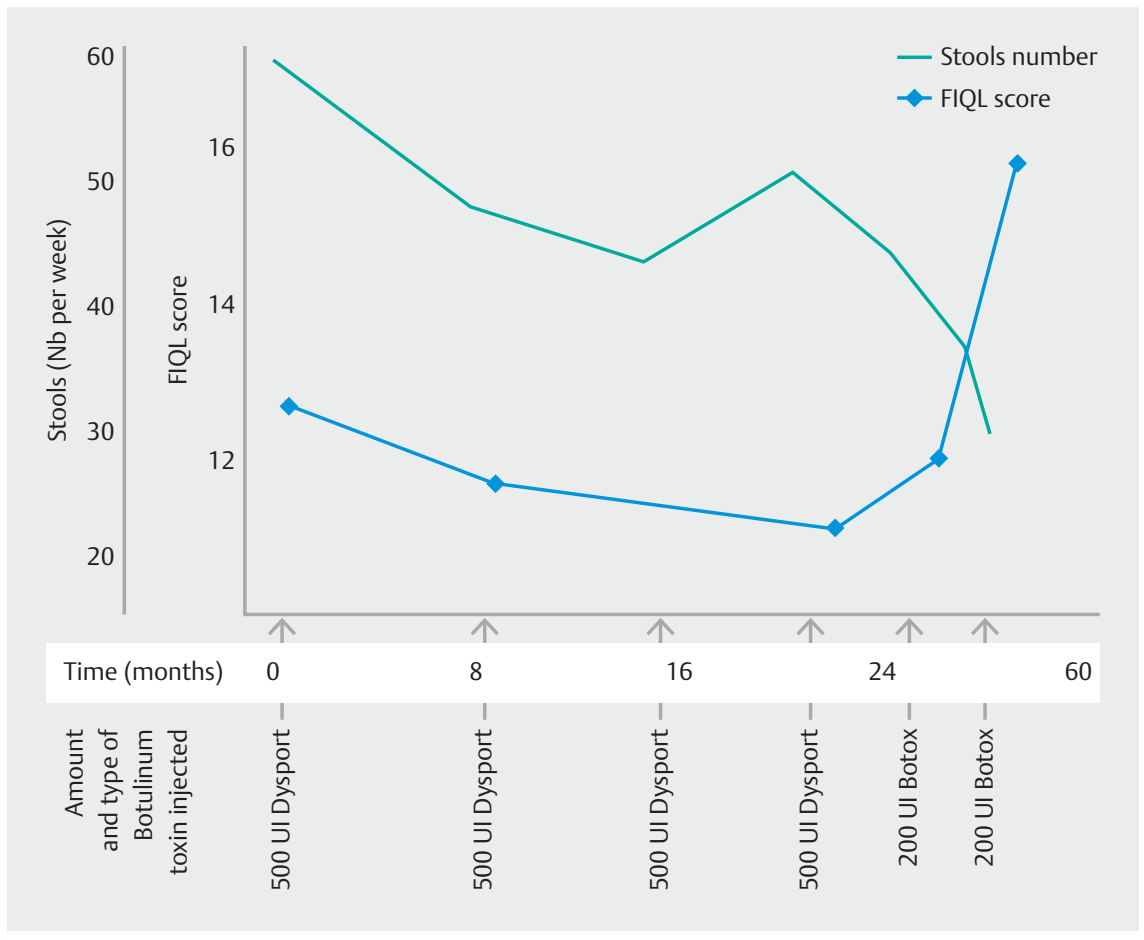

Fig. 1 Number of mean stools and quality of life evolution.

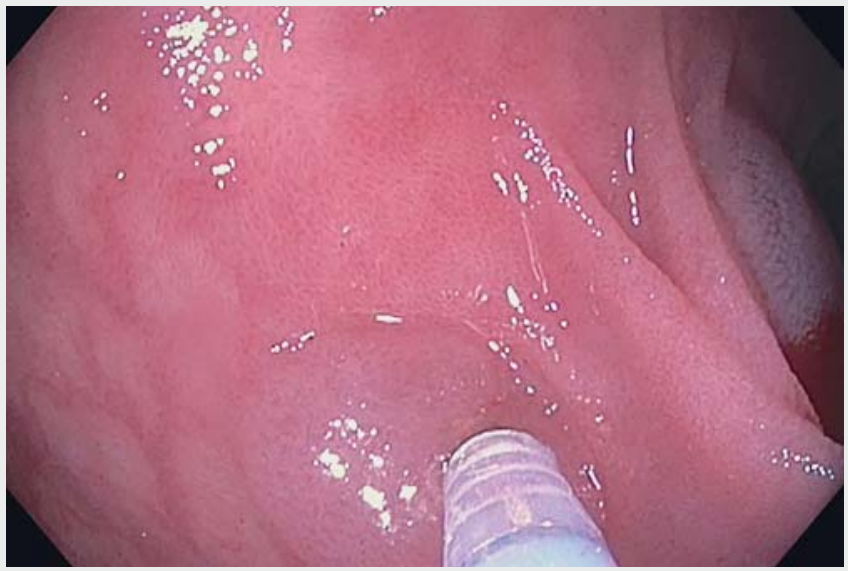

$\nabla$ Video 1 Endoscopic injections of botulinum toxin A for treatment of fecal incontinence in patient after ileoanal anastomosis. 
of 36.7 stools per week. The Cleveland score was 6 and fecal incontinence quality of life score was 15.8 . At month 29 , a new injection of 200 UI Botox was administered. Maintenance injections will be planned according to the patient's symptoms. No adverse effect was noted. When medical treatment fails, therapeutic options for fecal incontinence after ileoanal anastomosis are scarce and mainly involve surgery and ileostomy. Here we propose a well-tolerated endoscopic approach using the same procedure as in the colon [4]. The clinical result was relevant in this case and medical treatment remained unchanged. Great care should be exercised when performing submucosal Botulinum toxin A injections to prevent endoscopic perforation and eventual abdominal wall abscess. The duration response to this injection is not well defined. In our patient, we administered an injection when clinically needed. In fecal incontinence, the median duration of response to Botulinum toxin A injection is 4.5 months and shorter in patients with a neo-reservoir than in patients with their native rectum [4].

Endoscopy_UCTN_Code_CPL_1AM_2AH

\section{Competing interests}

The authors declare that Guillaume Gourcerol have received research subsidies from Allergan. The remaining authors declare that no conflicts of interest exist.
The authors

Nicolas Richard ${ }^{1}$, Paul Basile ${ }^{1} \stackrel{\oplus}{\text {, Guillaume }}$

Gourcerol ${ }^{1,2}$

1 Department of Hepatogastroenterology, Rouen University Hospital, Rouen, France

2 Department of Digestive Physiology, Rouen University Hospital, Rouen, France

\section{Corresponding author}

\section{Nicolas Richard, MD}

CHU de Rouen, Service d'Hépatogastroentérologie, 1 rue de Germont, 76000 Rouen, France

Fax: +33-2-32-88-56-50

nicolas.richard26@gmail.com

\section{References}

[1] Desprez C, Melchior C, Wuestenberghs F et al. Pyloric distensibility measurement predicts symptomatic response to intrapyloric botulinum toxin injection. Gastrointest Endosc 2019; 90: 754-760

[2] Cappell MS, Stavropoulos SN, Friedel D. Updated systematic review of achalasia, with a focus on POEM therapy. Dig Dis Sci 2020; 65: 38-65

[3] Kyriakakis R, Kelly-Schuette K, Hoedema R et al. What predicts successful nonoperative management with botulinum toxin for anal fissure? Am J Surg 2019; 219: 442-444

[4] Gourcerol G, Bénard C, Melchior C et al. Botulinum toxin: an endoscopic approach for treating fecal incontinence. Endoscopy 2016; 48: 484-488
Bibliography

Endoscopy 2022; 54: E460-E461

DOI 10.1055/a-1625-4613

ISSN 0013-726X

published online 27.9.2021

(c) 2021. Thieme. All rights reserved.

Georg Thieme Verlag KG, Rüdigerstraße 14 70469 Stuttgart, Germany

\section{ENDOSCOPY E-VIDEOS}

https://eref.thieme.de/e-videos

口厚回 Endoscopy E-Videos is an 畒 靣船: reporting on interesting cases and new techniques in gastroenterological endoscopy. All papers include a high quality video and all contributions are freely accessible online. Processing charges apply (currently EUR 375), discounts and wavers acc. to HINARI are available.

This section has its own submission website at https://mc.manuscriptcentral.com/e-videos 